\title{
ANAESTHESIA FOR SURGICAL REMOVAL OF PULMONARY CYSTS IN CHILDREN*
}

\author{
Thomas J. McCaughey, M.B., B.CH., D.A. $†$
}

LUNG CYSTS requiring surgery in infants and children are uncommon. Some can be diagnosed and removed fairly easily. Others present great problems in diagnosis and may have to be operated upon as emergencies. If the anaesthetist is not aware of the problems involved, the outcome may well be fatal.

\section{LITERATURE}

Apparently a pulmonary cystic condition was described first by Fontana ${ }^{1}$ in 1638. It is surprising to find little in the anaesthetic literature on this topic. Gray and Edwards ${ }^{2}$ reported their views in 1948. Otherwise most of the papers are in the surgical or paediatric journals. Fischer ${ }^{3}$ reported the first successful lobectomy in an infant of one month of age in 1943. He used local anaesthesia. In 1946 Robert Gross ${ }^{4}$ reported the first successful pneumonectomy in an infant three weeks old. For anaesthesia cyclopropane was given by face mask without endotracheal intubation. Burnett and Caswell ${ }^{5}$ described a lobectomy for pulmonary cysts in an infant 15 days of age, in 1948. This was the record for the youngest at that time. Thoracotomy was performed under local anaesthesia with $1 / 4$ per cent metycaine and "positive pressure oxygen by face mask." They said they were afraid to intubate the trachea in an infant so young. Colin Ferguson ${ }^{6}$ reviewed, in 1959, the cases recently operated upon at the Children's Hospital, Winnipeg. He mentioned the anaesthetist's problems. Willis Potts ${ }^{7}$ of Chicago wrote on lung cysts in his book The Surgeon and the Child published in 1959. He does not have anything to say about anaesthesia for these cases.

\section{Classification}

The literature is quite confusing on the classification of lung cysts. Reports have suggested that most of these cysts are congenital in origin. This is probably wrong. Conway's ${ }^{1}$ recent review suggests that most lung cysts are acquired as the result of bronchial inflammation and obstruction and very few are truly congenital in origin. Some believe that cysts are common in the lungs in the newborn period, and spontaneous regression is the rule. Postpneumonic lung cysts are known to be fairly common in children. Almost all of them disappear also if left alone. The diagnosis can often only be made by microscopic examination. Even then vital evidence may have been destroyed in removing the cyst.

\footnotetext{
"Presented at Western Division Meeting, Canadian Anaesthetists' Society, held in Winnipeg, Manitoba, in March, 1961.

†Anaesthetist-in-Chief, The Children's Hospital, Winnipeg, Manitoba. Lecturer, Department of Surgery, University of Manitoba.
} 


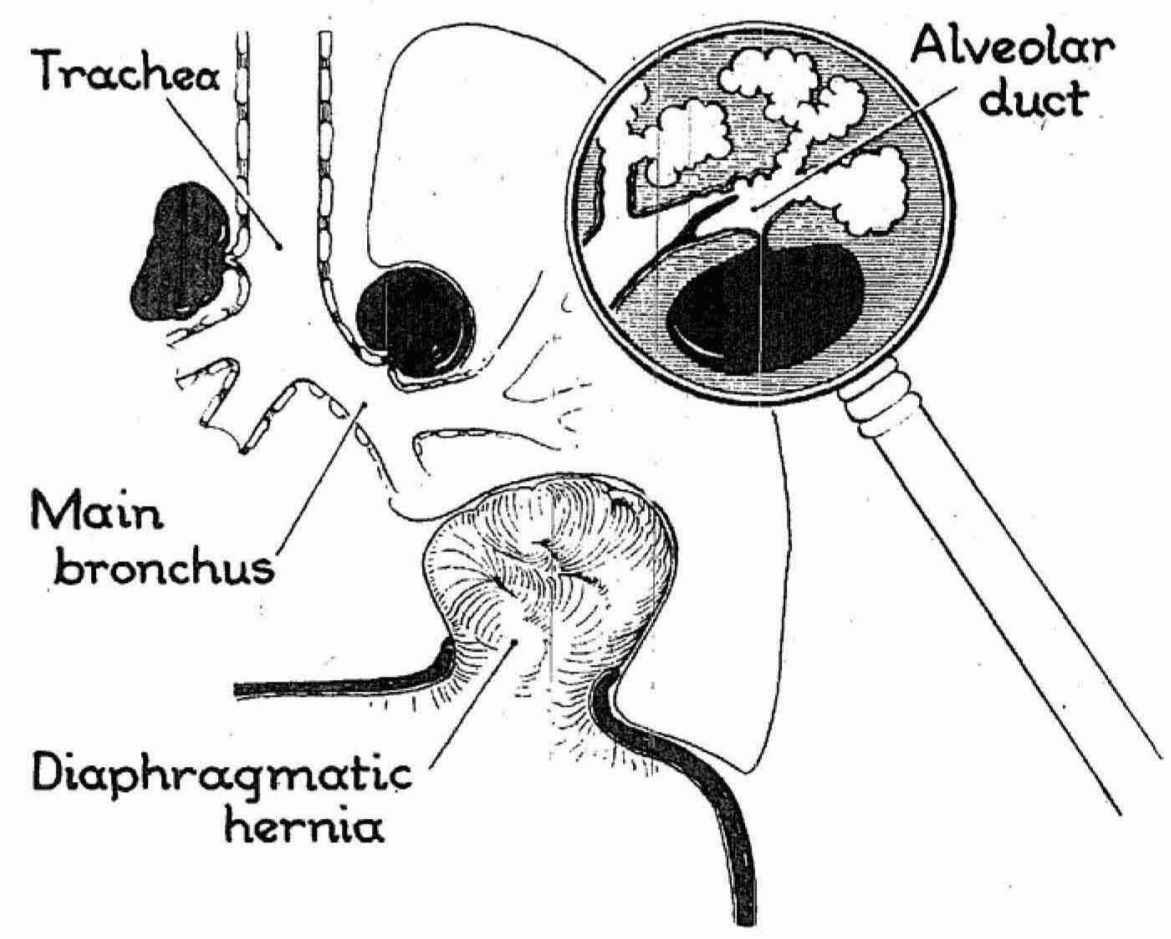

Figure 1

For the anaesthetist, some sort of anatomic classification is best (Fig. 1). True congenital bronchial cysts arise from the trachea or bronchus and are quite rare. Potts reports only three. They are typically filled with mucoid material and are not tension cysts. They may press upon the trachea or bronchus from outside and kink or obstruct it. They do not usually present a severe anaesthetic problem. However, since a deficiency of the wall of the trachea or bronchus is sometimes associated with them, a tracheopleural or bronchopleural fistula may occur in their removal. ${ }^{7}$

The anaesthetist may have more problems with cysts occurring at the periphery of the lung. Here a flap valve mechanism often seems to operate. The term "localized lobar or lobular emphysema" describes the result in some cases. The treatment of this condition is usually surgical. When large air-filled lung cysts occur in small infants a similar mechanism is probably to blame. These give the anaesthetist his greatest worry.

Severe bronchiectasis resulting in a lung honeycombed with cysts occurs in older children mostly and presents distinct anaesthetic problems. In the differential diagnosis we must mention other thoracic cysts and pseudocysts such as congenital diaphragmatic hernia, intestinal reduplications in the thorax, cystic hygroma involving the mediastinum, and some rare tumours. From our point of view, the vast majority of these cysts present no special problem and can be ignored.

\section{Case Histories}

In this series we encountered two true congenital bronchial cysts, two cases of localized lobular emphysema, one postpneumonic pneumatocoele, two expanding air cysts, one in an infant and one in a three-year-old girl, and finally, one bad bronchiectasis. These eight patients are all alive and well, and their cases are presented in more detail below. 


\section{Congenital Bronchogenic Cysts}

Cuse I.-This was a five-week-old baby girl who had marked stridor from one week of age. This became so severe that the baby had to be put in hospital. A barium swallow showed marked displacement of the oesophagus to the right and marked anterior displacement of the trachea with considerable narrowing. It was necessary to perform right lateral thoracotony as an emergency operation. A large mass between the trachea and oesophagus, fairly closely adherent to both structures and measuring about 2 inches by $1 \%$ inches, was dissected out. No perforation of the trachea or oesophagus was produced. In this case anaesthesia was controlled using intermittent succinylcholine from the beginning. Recovery was satisfactory. On microscopic examination this proved to be a true congenital bronchogenic cyst.

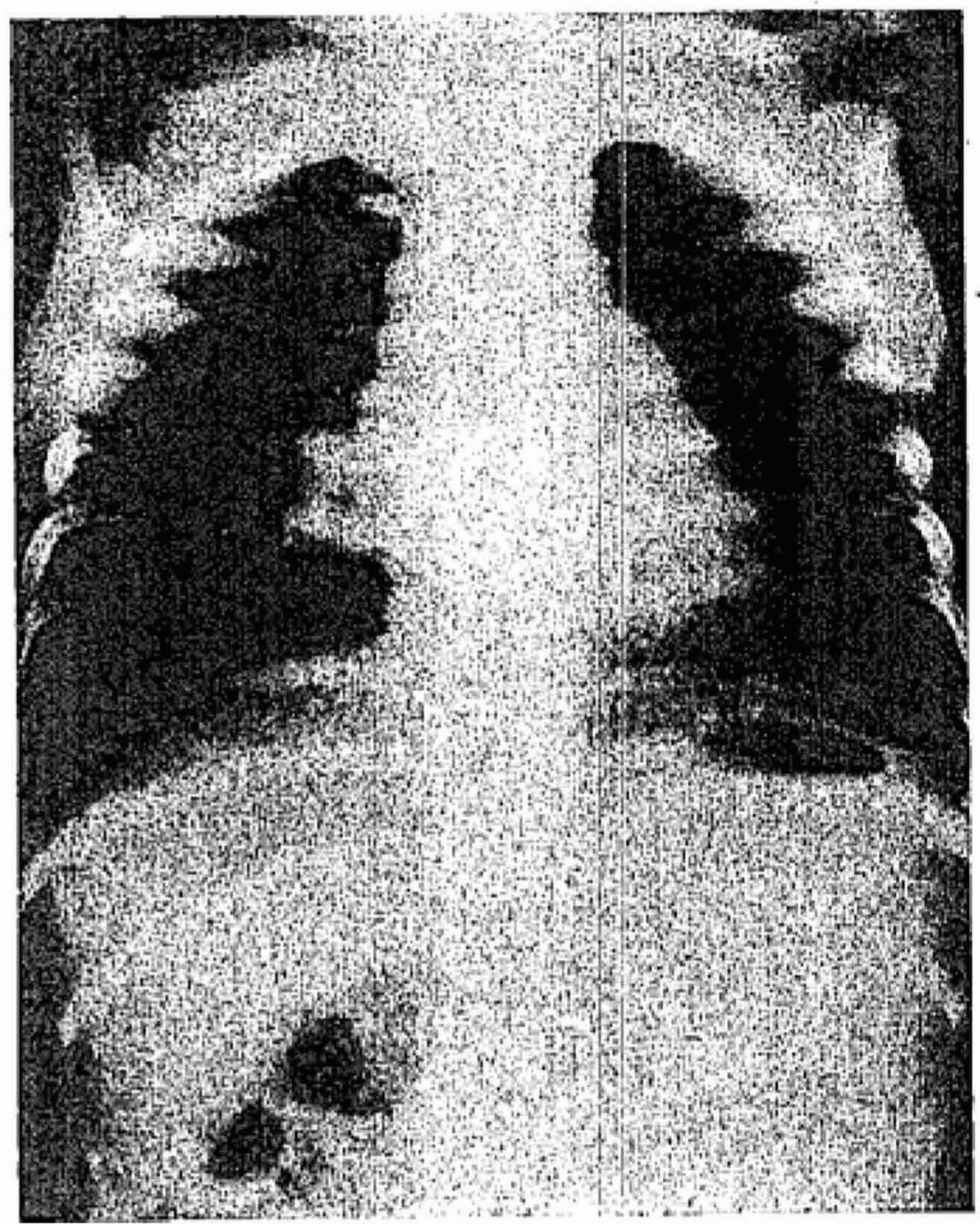

Figure 2

Case 2.--This seven-month-old Eskimo girl had a small, round, dense shadow picked up on a routine chest X-ray (Fig. 2). On follow-up this was seen not to be expanding and the baby had no respiratory distress. Anaesthesia presented no great problem here and respirations were controlled from the beginning. The cyst seemed to have no connections with the lungs and was easily removed. On microscopic examination it was seen to be lined with ciliated columnar epithelium similar to that of the respiratory tract. This was a true bronchogenic cyst.

\section{Localized Lobar or Lobular Emphysema}

In this condition a lobule or part of a lobe shows emphysematous change with bullae formation. On radiological examination of the chest this appears as airfilled cystic areas through which some lung markings can still be seen. 


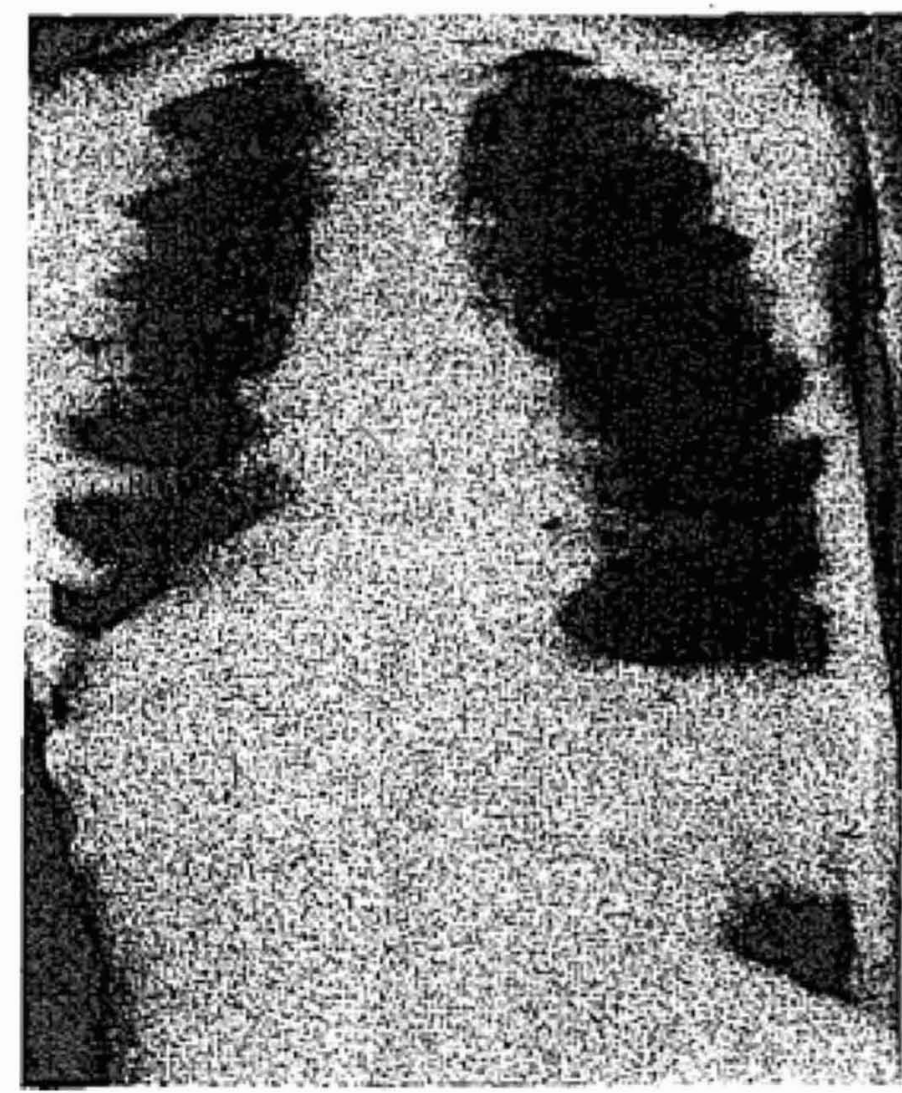

FIGURE 3A

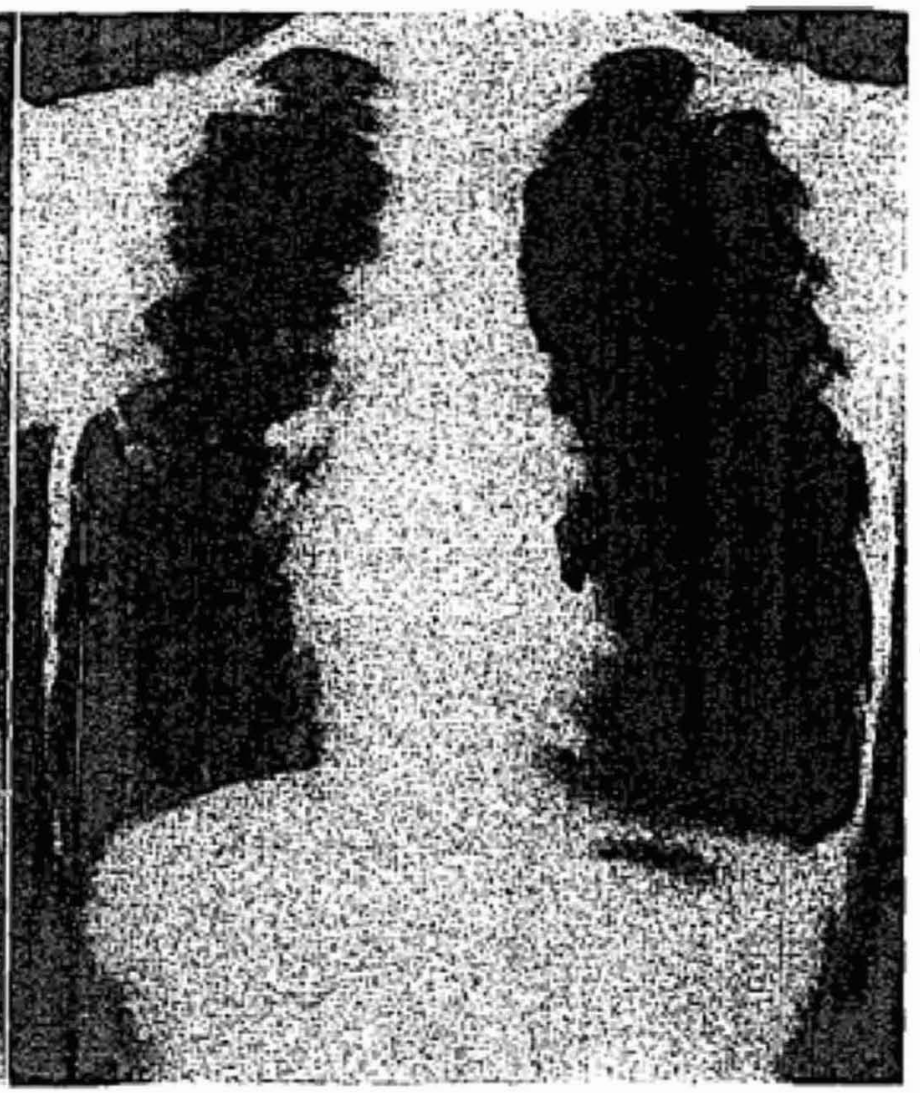

Figune 3B

Case 3.-This five-yeur-old girl was asymptomatic, apart from some dyspnoea on exertion (Fig. 3A). She was discharged and did not return for a year, at which time another chest $X$-ray (Fig. $3 B$ ) was taken. The emphysematous area now filled most of her left chest. She was hyperresonant and had diminished breath sounds over this area but was otherwise still in no grent distress. The anaesthetist decided to keep spontaneous respiration till the chest was open. Therefore cyclopropane and ether were given and an endotracheal tube easily passed. Once the chest was open the respiritions were controlled. A distended preumatocoele was excised from the left lower lobe and the lung could be expanded immediately to fill the chest. Recovery was uneventful. In view of the great size of this cyst it was probably safer not to use positive pressure breathing.

Case 4.-Figure 4 show's the bronchogram of a seven-year-old boy who had a history of pneumonia when a small child, followed by chronic bronchitis with sputum. He was suspected to have bronchiectasis. Anaesthesia was given for two bronchoscopies and a bronchogram, and fiually for thoracotomy. For the bronchoscopies anaesthesia was mainly with ether and halothane. For bronchograms we use two techniques mainly, one with halothane, the other an apnoeic technique with controlled respiration employing succinylcholine by intermittent injection. In this case we used controlled respiration without any trouble. For the thoracotomy, controlled respiration was used right from the beginning. When the chest was open we could see the emphysematous region of the posterior basal segment. This could be inflated by increasing the positive pressure and it collapsed spontaneously when pressure was released. It was easy for the surgeon. to resect. The patient made a good recovery.

\section{Postpneumonic Pneumatocoele}

Case 5.-This baby boy at three months of life developed pustules on the skin and later a left lower lobe pneumonia, which cleared up with antibiotics, without hospitalization. However, he began to wheeze, and chest radiography showed at first a small cyst 

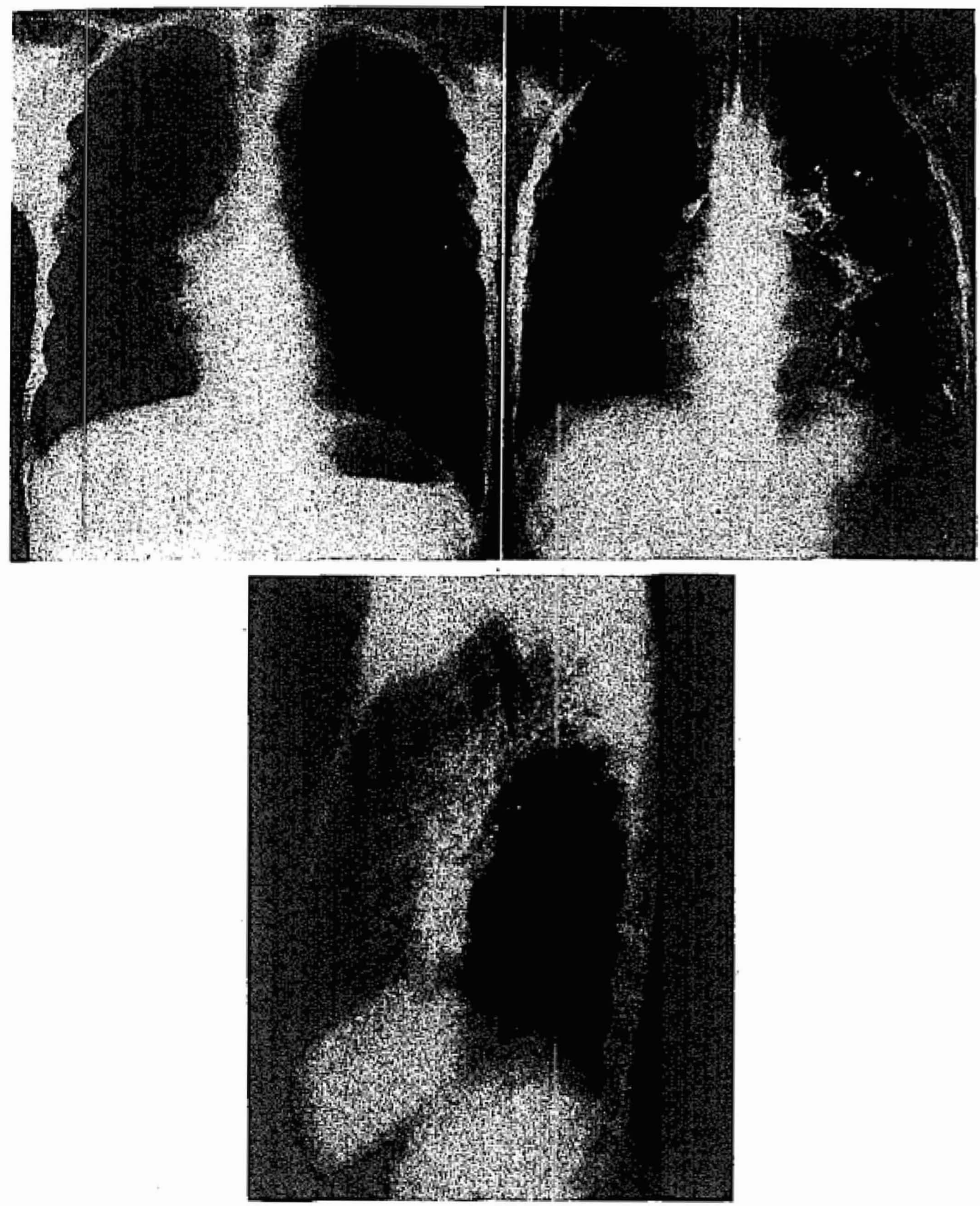

Figure 4

of the lower left lobe, which later grew in size. By the time he was admitted to hospital the cyst occupied most of his left chest. (Fig. 5). In spite of this, the infant had very little respiratory distress. Anaesthesia was essentially with nitrous oxide, oxygen, and ether. Endotracheal intubation was done under ether and respirations were spontaneous till the chest was open. Once the cyst had been delineated respirations were controlled, using cyclopropane and oxygen. The cyst was excised from a small area, about the size of a fifty-cent piece, from the left lower lobe and the lung was expanded at once very easily to fill the chest. Postoperative progress was uneventful. 

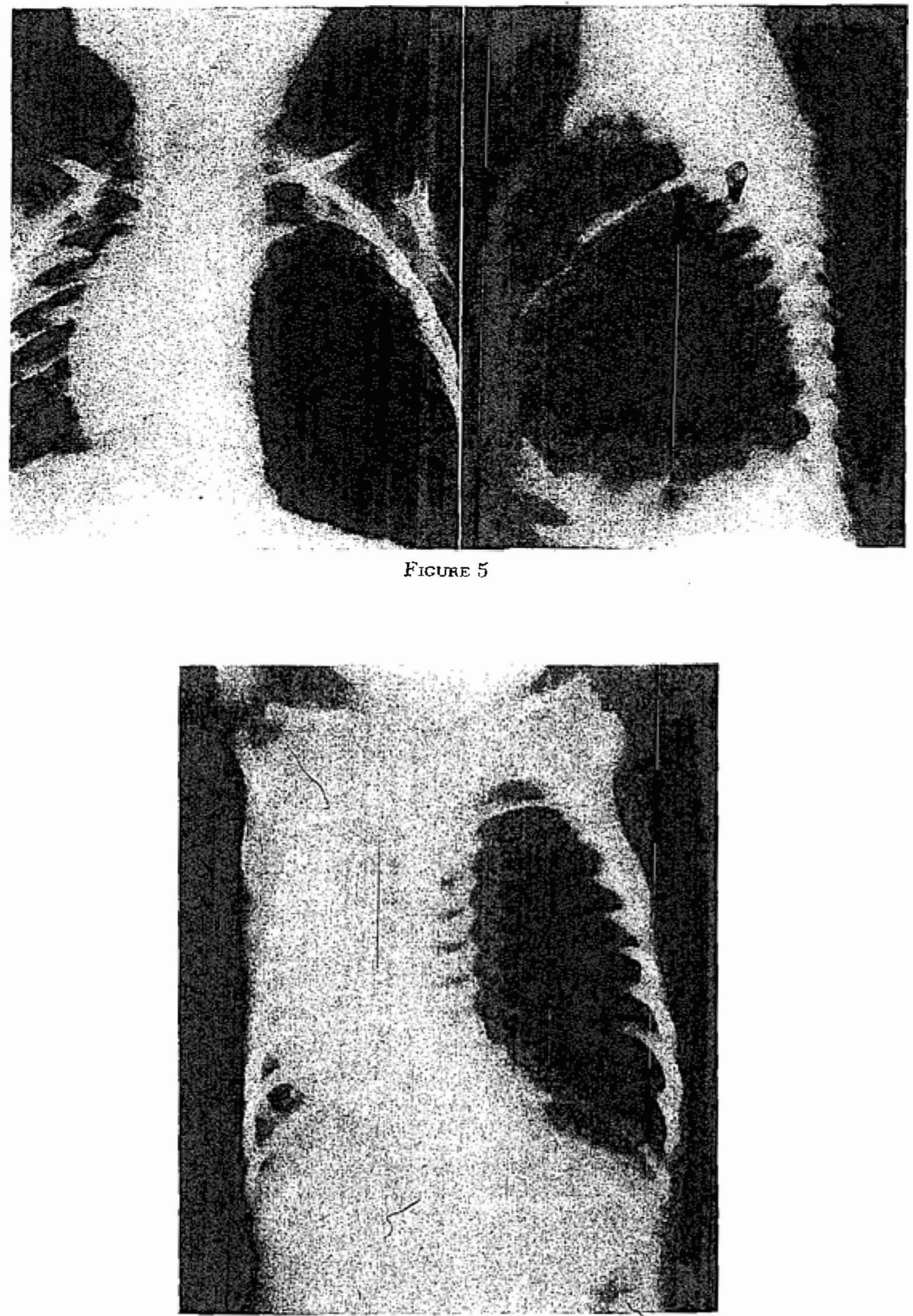

Ficime 6 


\section{Expanding Giant Air Cysts}

Case 6.-This patient was apparently normal at birth, but at ten days of life she had an upper respiratory infection. By the time of admission she was in severe distress (Fig. 6). Emergency thoracotomy was performed. Because of the obvious expanding naturc of this air cyst, the anaesthetist did not want to use positive pressure breathing. The infant was, therefore, intubated awake and anaesthesia maintained with cyclopropane and oxygen. On positioning of the patient, the condition began to deteriorate and bradycardia was noticed. The chest was quickly opened, the cyst punctured, and controlled respiration assumed. The condition of the patient improved at once, and the cyst was excised leaving normal lung tissues.

Case 7.-This was a three-year-old girl. Three days before admission she developed a cough and fever. On admission she had a large right pneumothorax (Fig. 7). She was thought to have a staphyloccal pneumonia with rupture of a subpleural abscess. Since these patients very seldom need surgical interference she was treated conservatively by
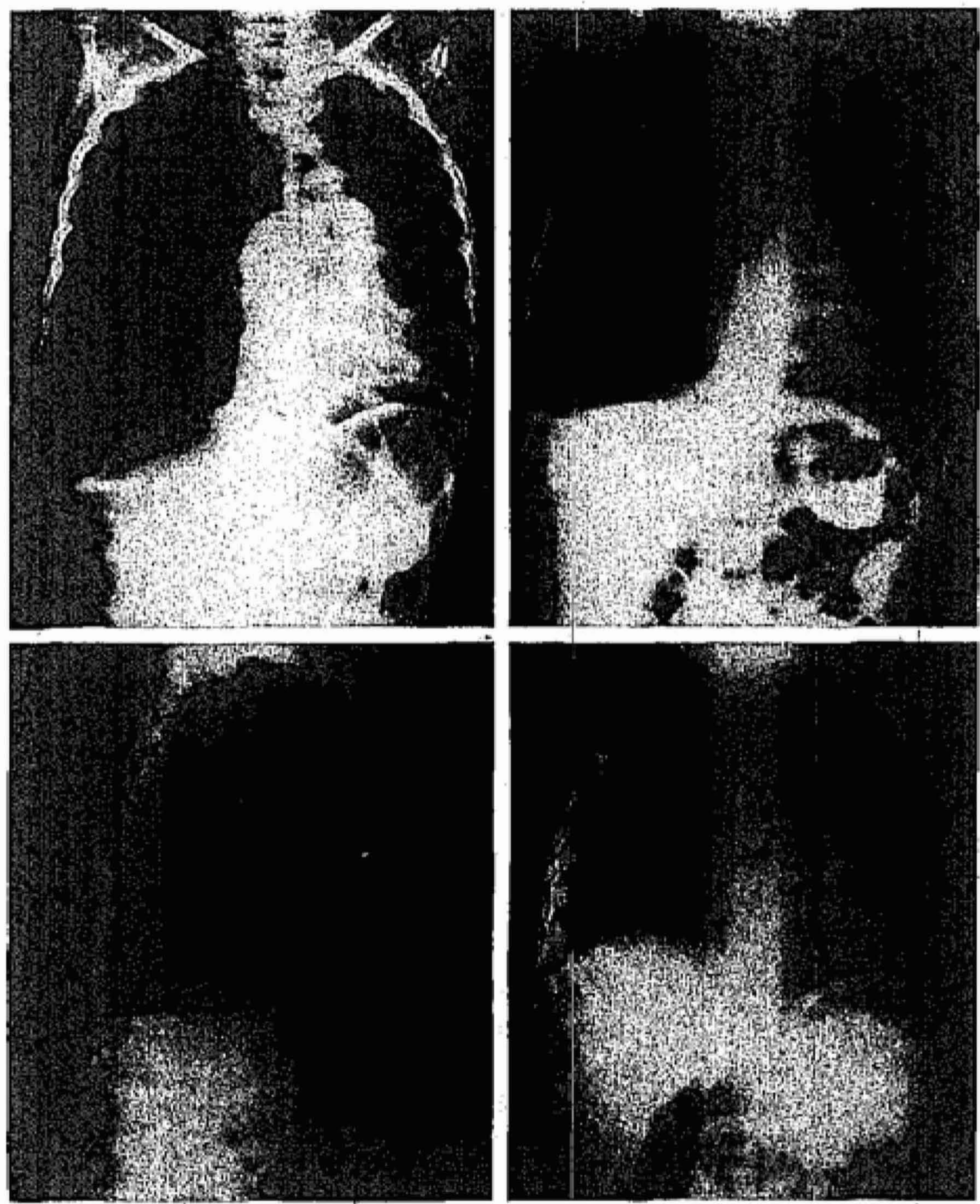

Figure 7 
underwater chest dranage The pneumothorax dad not resolve and after about sin days the chest radiograph shawed development of a large pneumatocoele in the right upper lung field Bronchoscopy was performed in the hope of finding some ball valve mechanism that could be removed Anesthesı ? for this was with ether spontaneous respuration being mantaned throughout This uent off uneventfully and as one might expect the bronchoscopist was unable to report any significant findungs Even the best bronchoscopist can only examine the trunh and main branches of the tracheobronchual tree Thoractomy and right upper lobectom? were necessary During anaesthesi? succinylcholme was given for endotracheal intubation and intermittent positive pressure was used tall spontaneous respiration returned When the patient was turned on her left sıde some distress was momentarily observed Further displacement of the mediastinum perhaps with kinking of the trache's due to the position may have ocen responsible However this disappeared almost at once and is soon as the chest was open respurations were controlled with intermittent positive pressure breathing Surgery was uneventful and convalescence rapid In thrs case one had the impression that controlled respiration might have been issumed from the begmung withont trouble

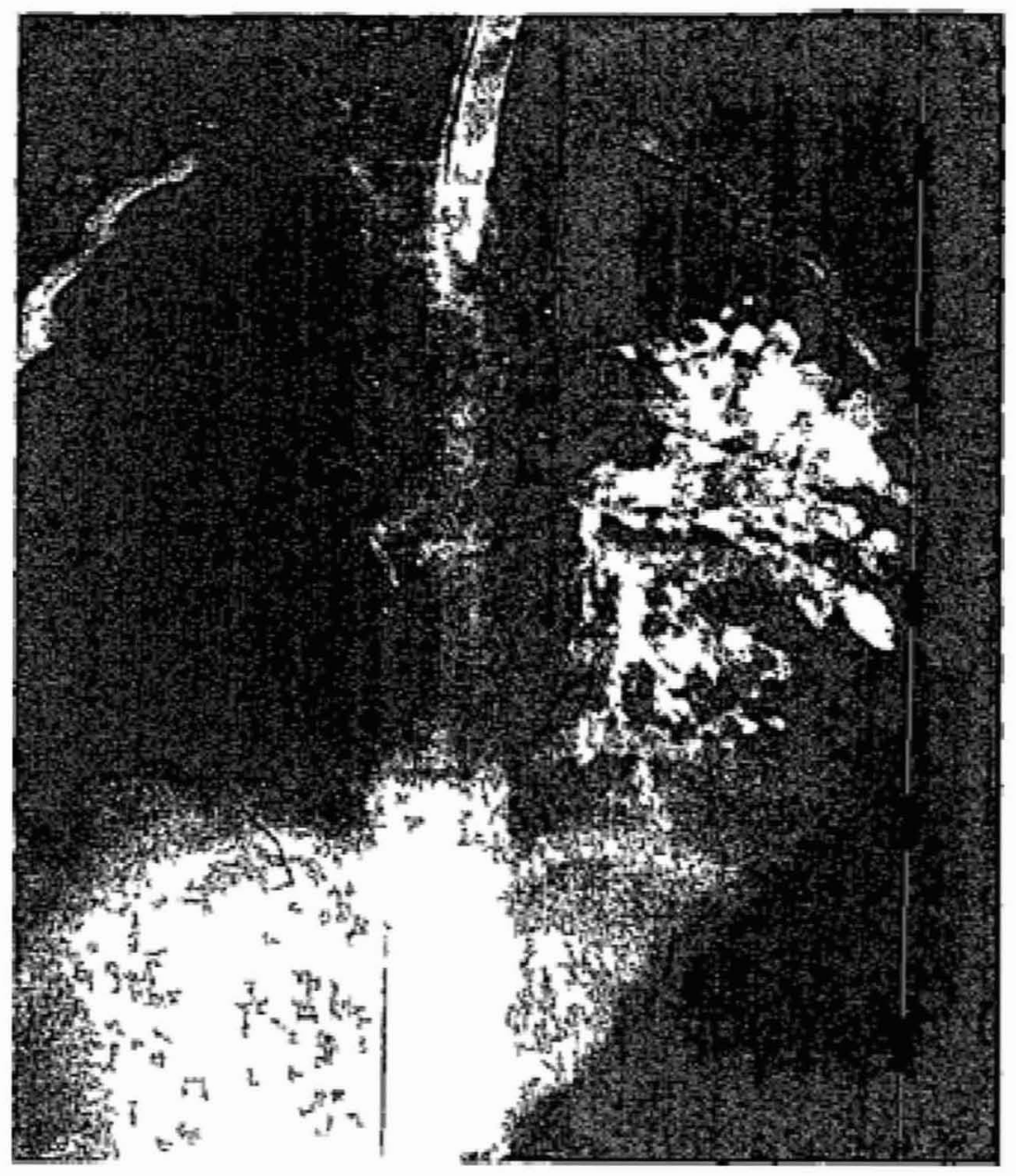

Firune $S$

\section{Bronchiectasis Honeycombed Lung}

Case 8-This was a two year old Eskimo gul who suffered from repeated bouts of pneumonia, and contunuausly coughed up pus (Fig 8) She required anaesthesia for bronchoscopy, two bronchograms two antral washouts and finally for thoracotomy and pneumonectomy She presented the man problem common to all bad, wet lung cases namely the control of sputum During the thoracotomy she was in trouble in spite of positioning Crequent suctioning and fight lung anaesthesia till the surgeon secured the left mann bronchus Anaesthesia was then relativelv easy She did well The left lung was honeycombed with pus filled cr sts (Fig 9) 


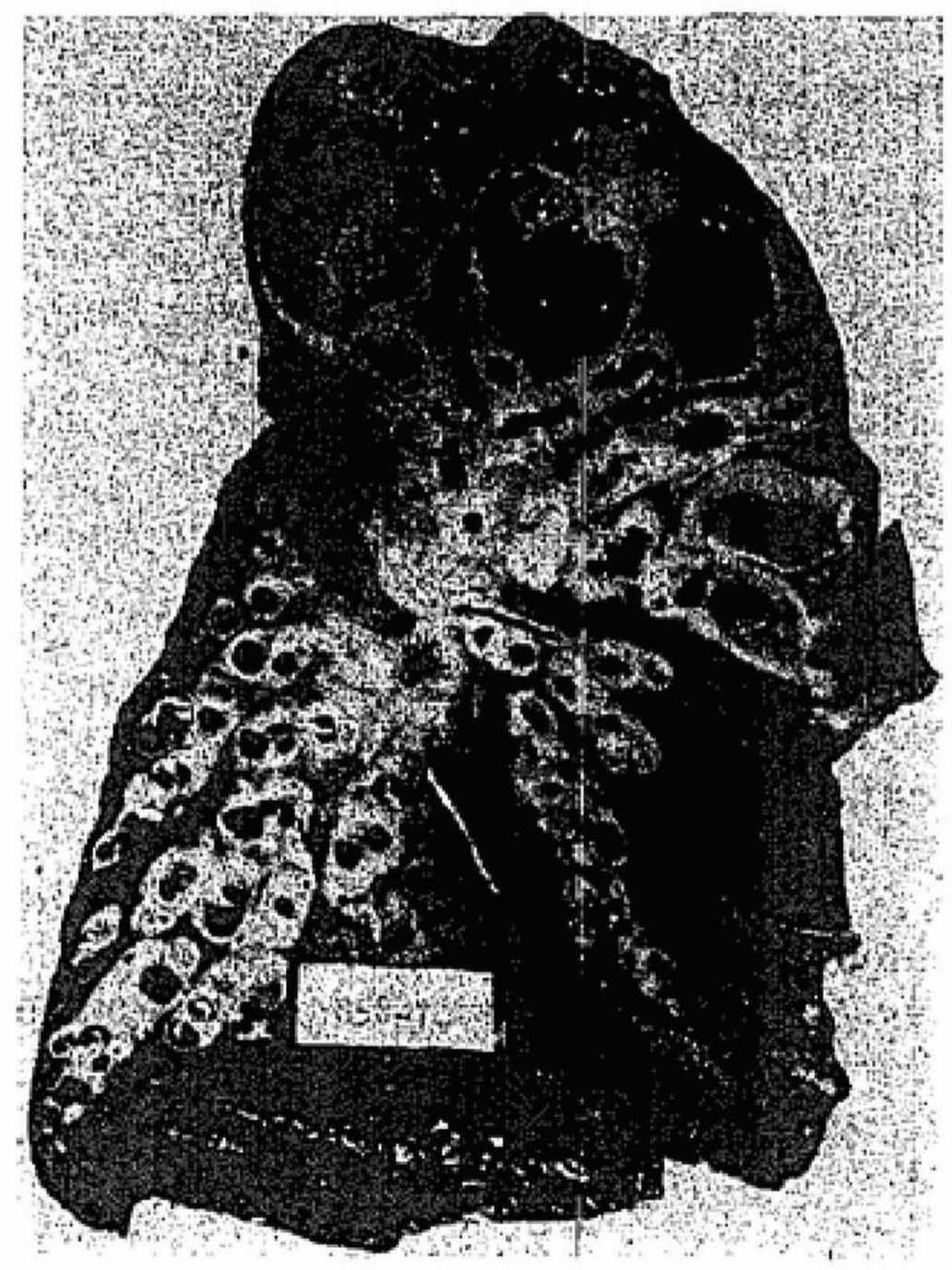

Ficure 9

\section{Manacement of Anaestyesia}

The anaesthetist must try to understand the basic mechanism involved in producing the individual lung cyst or cysts. Attaching a diagnostic label is of secondary importance. Time is very well spent in studying roentgenograms of the chest, serially when these are available. Nowadays no anaesthetist would undertake the management of one of these cases without endotracheal intubation. The decision as to whether to have spontaneous or controlled respiration depends to some extent on the individual case. When the air cyst is expanding, it may seem advisable to allow spontaneous breathing. However, at the first sign of deterioration, controlled respiration with a high concentration of oxygen must be assumed. In this case the surgeon must be prepared to insert a wide-bore needle into the cyst or to proceed rapidly with thoracotomy and isolate or deflate the cyst. A good argument can be made for the use of controlled respiration in all these patients. Even with a potentially expanding oyst the opposite main bronchus can

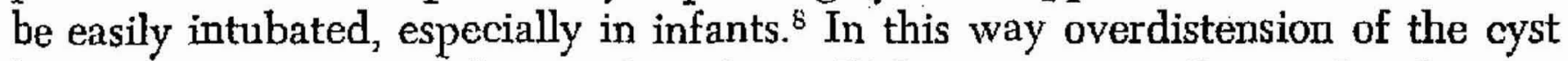
by positive pressure can be avoided. Controlled respiration will provide adequate ventilation and oxygenation in the presence of diminished-functioning lung tissue. On the other hand, an infant with a large ling cyst, if allowed to breathe spontaneously, will often be inadequately anaesthetized and ventilated; the resultant struggling can rapidly expand the lung cyst and the condition of the infant then deteriorates rapidly. 
During surgery the use of positive pressure helps the surgeon to delineate the cystic area to be removed. After excision of the cyst the use of intermittent positive pressure breathing will help the surgeon to detect and seal off leaks from the lung. In spite of this, bronchopleural fistulae may persist for some time postoperatively. In spite of its having been collapsed by pressure from a cyst for months it is often surprisingly easy to expand underlying lung. Every reasonable effort must be made to do this at the time of surgery.

Postoperatively all these children are placed in an atmosphere of maximum humidity with oxygen if necessary. Intermittent positive pressure using a Bird Respirator may be necessary to maintain inflation of previously collapsed lung.

\section{SUMMARY}

The literature on anaesthetic considerations in the removal of lung cysts in infants and children is scarce. A simple classification of these cysts on the basis of the anatomic mechanism involved is desirable. The history and a study of the chest roentgenograms will help the anaesthetist to understand this mechanism in each case. Spontaneous respiration may seem more desirable with expanding cysts, but there is a good argument for using controlled respiration under general anaesthesia in all cases. The cases of eight patients with different types of lung cysts are presented.

\section{RÉSUMÉ}

Il y a presque rien dans la littérature de l'anesthésie sur le sujet des kystes pulmonaires chez les nouveaux-nés et chez les enfants. Les premiers rapports remontent il y a quinze ans environ dans la littérature chirurgicale, mais la description de la technique de l'anesthésie n'était pas du tout satisfaisante.

L'anesthésiste doit essayer de comprendre le mécanisme de l'anatomie impliquée avec la formation de ces kystes. Ce mecanisme suggère une technique exacte dans l'administration de l'anesthésie. Nous avons décrit ici huit cas de kystes du poumon rencontrés récemment à l'Hôpital des Enfants de Winnipeg. Tous sont en vie et en bonne santé.

Quand le kyste pulmonaire est du type qui s'étend rapidement, associé généralement avec le mécanisme d'une valvule, il semble désirable de garder une respiration spontanée pendant l'anesthésie. Cependant, pour sa plus grande sûreté, il y a tendance à se servir d'une respiration controlée dans tous les cas. Il est nécessaire parfois de passer un tube dans la brohche opposée au kyste.

Il est obligatoire d'essayer de dilater le reste du poumon après l'intervention chirurgicale et de le garder dilaté après l'opération. Enfin des fistules communicantes des plèvres aux bronches peuvent survenir.

\section{ACKNOWLEDGMENTS}

My deepest thanks are due to Professor Colin Ferguson for helpful advice, and to Doctor L. L. Whytehead and Doctor M. B. Perrin whose cases are also reported here; also to Miss Nancy Joy, Medical Artist, Department of Surgery, University of Manitoba, and to Mr. Tony Gibson, Photographer, The Children’s Hospital. 


\section{REFERENCES}

1. Conway, D. J. The Origin of Lung Cysts in Childhood. Arch. Diseases in Childhood, 26: 504 (1951).

2. Gray, T. C., \& Edwards, F. R. Anaesthetic Problems Associated with Giant Tension Cysts of the Lung. Thorax 3: 237 (1948).

3. Fischer, C. C.; Tropea, F., JR.; \& Baney, C. P. Congenital Pulmonary Cysts. Report of an Infant Treated by Lobectomy with Recovery. J. Pediatrics 23: 219 (1943).

4. Gross, R. F. Congenital Cystic. Lung. Successful Pneumonectomy in a Three-week-old Baby. Ann. Surg. 123: 229 (1946).

5. Burnetr, W. E., \& Caswell, H. T. Lobectomy for Pulmonary .Cysts in a Fifteen-day-old Infant with Recovery. Surgery 23: 84 (1948).

6. Ferguson, C. C. Chest Shadows of Surgical Significance. Presented at the Meeting of the Pennsylvania State Medical Society, October 22, 1959. The Baker Laboratories, Inc., Cleveland, Ohio.

7. Potrs, W. J. The Surgeon and the Child. 1st ed. Philadelphia: Saunders (1959).

8. Macartney, Hugh H., Vancouver, B.C. Personal communication. 